\title{
Auxotrophy Accounts for Nodulation Defect of Most Sinorhizobium meliloti Mutants in the Branched-Chain Amino Acid Biosynthesis Pathway
}

\author{
Maria de las Nieves Peltzer, ${ }^{1}$ Nicolas Roques, ${ }^{2}$ Véréna Poinsot,,${ }^{3,4}$ O. Mario Aguilar, ${ }^{1}$ Jacques Batut, ${ }^{2}$ \\ and Delphine Capela ${ }^{2}$ \\ ${ }^{1}$ Instituto de Biotecnologia y Biologia Molecular, CCT-La Plata, Universidad Nacional de La Plata, Facultad de Ciencias \\ Exactas, Calles 47 y 115, 1900-La Plata, Argentina; ${ }^{2}$ Laboratoire des Interactions Plantes-Microorganismes, \\ UMR CNRS-INRA 2594/441, F-31320 Castanet Tolosan, France; ${ }^{3}$ Université Paul Sabatier, UMR 5623, Laboratoire \\ des IMRCP, F-31062 Toulouse, France; ${ }^{4}$ CNRS, UMR 5623, Laboratoire des IMRCP, F-31062 Toulouse, France
}

Submitted 24 February 2008. Accepted 1 June 2008.

\begin{abstract}
Some Sinorhizobium meliloti mutants in genes involved in isoleucine, valine, and leucine biosynthesis were previously described as being unable to induce nodule formation on host plants. Here, we present a reappraisal of the interconnection between the branched-chain amino acid biosynthesis pathway and the nodulation process in $S$. meliloti. We characterized the symbiotic phenotype of seven mutants that are auxotrophic for isoleucine, valine, or leucine in two closely related $S$. meliloti strains, 1021 and 2011. We showed that all mutants were similarly impaired for nodulation and infection of the Medicago sativa host plant. In most cases, the nodulation phenotype was fully restored by the addition of the missing amino acids to the plant growth medium. This strongly suggests that auxotrophy is the cause of the nodulation defect of these mutants. However, we confirmed previous findings that $i l v C$ and $i l v D 2 \mathrm{mu}-$ tants in the $S$. meliloti 1021 genetic background could not be restored to nodulation by supplementation with exogenous amino acids even though their Nod factor production appeared to be normal.
\end{abstract}

Rhizobia are soil bacteria which are able to fix nitrogen in symbiotic association with leguminous plants. The fixation process occurs in a specialized organ, the nodule, which is the end point of a complex developmental program. The process starts with a molecular recognition system that enables specific rhizobia to enter root hairs. Most rhizobia penetrate the root through the formation of infection threads that cross several cell layers in the root. Simultaneously, root cortical cells divide and differentiate to form the nodule. Then, bacteria are released from the infection threads into the plant cells and, in some legumes, differentiate into nitrogen-fixing bacteroids.

Signal molecules involved in the early recognition process were previously identified. Flavonoid compounds present in root exudates induce activation of what are collectively called

Corresponding author: D. Capela; Telephone: +1 335612854 54; Fax: +1 335612850 61; E-mail: Delphine.Capela@toulouse.inra.fr

* The $e$-Xtra logo stands for "electronic extra" and indicates that three supplementary tables and two supplementary figures are published online.

This article is in the public domain and not copyrightable. It may be freely reprinted with customary crediting of the source. The American Phytopathological Society, 2008. nodulation genes (nod, nol, and noe genes), which are present in most rhizobia. The activity of nodulation proteins yields $\mathrm{N}$ acylated oligomers of $\mathrm{N}$-acetyl-D-glucosamine, known as Nod factors, which play a role in both nodule organogenesis and nodule colonization. The common nodulation genes nodABC are unique to rhizobia and are found in most rhizobia. Specific nodulation genes (nodMnolFGnodN, nodIJ, nodQPGEF, $n o d H$, and nodLnoeAB in Sinorhizobium meliloti) determine the specific structure of Nod factors and are characteristic of rhizobium species. However, only mutations in nodABC and $n o d H$ genes in $S$. meliloti lead to a strict $\mathrm{Nod}^{-}$phenotype (no nodule formation) on Medicago spp. host plants (Roche et al. 1991). Inactivation of other nodulation genes just delays nodulation or affects infection, sometimes in a plant-specific way (Ardourel et al. 1995; Debellé et al. 1986; Demont et al. 1993). For some mutants, the absence of nodulation phenotype might be due to gene redundancy in the genome (e.g., nodM and $n o d P Q)$. In $S$. meliloti, expression of the nodulation genes is regulated by three LysR-type NodD regulators. NodD1 and NodD2 are transcriptional activators that depend on plant inducers, flavonoids, and betaines, respectively. NodD3 activates nod genes independently of plant compounds and its expression depends on a complex regulation involving the regulatory proteins SyrM and NodD1 and the NtrBC two-component system which responds to the nitrogen status of the cell (Dusha and Kondorosi 1993; Maillet et al. 1990).

Apart from mutations in nodulation genes, very few mutations leading to a $\mathrm{Nod}^{-}$phenotype (no nodule formed) have been described in $S$. meliloti. Auxotrophic mutations in a number of amino acid biosynthetic pathways such as histidine, asparagine, cysteine, or arginine biosynthesis do not impair the ability of $S$. meliloti to initiate nodule formation (Randhawa and Hassani 2002), whereas several mutants that affect the biosynthesis of branched-chain amino acids (BCAA) isoleucine, valine, and leucine have repeatedly been shown to be defective in the initiation of nodule formation on host legumes (Aguilar and Grasso 1991; Hassani et al. 2002; Lopez et al. 2001; Pobigaylo et al. 2008; Sanjuan-Pinilla et al. 2002; Truchet et al. 1980). This suggested a specific and important role of the BCAA biosynthesis pathway in the nodulation process in $S$. meliloti.

Aguilar and Grasso (1991) first characterized a mutant in the $i l v C$ gene encoding a key enzyme in the isoleucine and valine biosynthesis which was unable to form nodules on alfalfa even when isoleucine and valine were added to the plant culture 
medium. Lopez and associates (2001) further demonstrated that both induction of nodulation genes by addition of the plant flavone luteolin and Nod factor production were strongly affected in this mutant. More recently, Hassani and associates (2002) showed that not only an ilvC mutant but also an $i l v I / B / G$ mutant in the $S$. meliloti Rmd201 strain were impaired for nodulation and infection processes on Medicago sativa. As in the Aguilar and Grasso study (1991), the $\mathrm{Nod}^{-}$phenotype of both mutants was not rescued by addition of exogenous isoleucine and valine. Another S. meliloti auxotrophic strain defective for host legume nodulation was identified by SanjuanPinilla and associates (2002). This strain was mutated in leuAl, the gene encoding the first enzyme of the leucine biosynthesis pathway; nodulation gene expression was also affected in this mutant. In this case, addition of leucine to the plant growth medium allowed the mutant to nodulate alfalfa roots, although with a slower kinetics than the wild-type strain. Truchet and associates (1980) also reported a leucine auxotrophic mutant in S. meliloti strain L5-30 that formed ineffective nodules, inside which mutants were sequestered in infection threads. It was also found that addition of leucine or leucine precursors restored the capacity of the mutants to invade plant cells and fix nitrogen. In contrast, two independent $i l v D \mathrm{mu}-$ tants that were auxotrophic for isoleucine and valine amino acids in strains 1021 and Rmd201 were found to be symbiotically active on Medicago plants (Aguilar and Grasso 1991; Hassani et al. 2002).

Hence, no clear picture emerged from these different studies regarding the link between BCAA synthesis and nodulation in S. meliloti (Supplementary Table S1 provides a summary of previously published data). In particular, it was not clear whether the entire isoleucine, valine, and leucine biosynthetic pathway is necessary for the nodulation process in S. meliloti or whether only certain enzymes or intermediary products of the pathway are required. Another question that remained unanswered was whether all the $\mathrm{Nod}^{-}$auxotrophic strains are impaired for Nod factor production and whether this could account for the nodulation defect of these strains.

Here, we present a complete reappraisal of the role of the BCAA biosynthesis pathway in the nodulation process in $S$. meliloti. In two different $S$. meliloti genetic backgrounds, we constructed or identified a set of mutants that were auxotrophic for isoleucine, valine, or leucine and that affected almost all enzymatic steps of the biosynthetic pathway. We then systematically and concomitantly assessed their symbiotic phenotype on host plants in the absence or presence of the required amino acids. We also systematically monitored their ability to express nodulation genes in response to the flavone, luteolin.

\section{RESULTS}

\section{Identification of the $S$. meliloti genes involved in the BCAA biosynthesis pathway.}

The biosynthesis of BCAA valine, isoleucine, and leucine occurs through a parallel set of reactions beginning with pyruvate and $\alpha$-ketobutyrate (Fig. 1). Four common enzymes are required for the biosynthesis of isoleucine and valine: an acetohydroxy acid synthase (AHAS), an acetohydroxy acid isomeroreductase, a dihydroxy-acid dehydratase, and a BCAA aminotransferase. In Escherichia coli, these enzymes are encoded by the ilvBN (AHAS isozyme I), ilvGM (AHAS isozyme II), $i l v I H$ (AHAS isozyme III), ilvC, $i l v D$, and $i l v E$ genes, respectively. Leucine is formed from $\alpha$-ketoisovalerate, an intermediate in valine biosynthesis. Leucine biosynthesis requires three additional enzymes: $\alpha$-isopropylmalate synthase, $\alpha$-isopropylmalate isomerase, and $\beta$-isopropylmalate dehydrogenase. These enzymes are encoded by leuA, leuC, leuD, and
leuB genes in E. coli. Likely orthologs of all E. coli genes have been identified on the $S$. meliloti genome, except for genes encoding the two regulatory subunits of AHAS-I and -II, ilvN and ilvM. Some of the ilv and leu genes have paralogs in $S$. meliloti, including $3 i l v B, 5 i l v D, 2 l e u A$, and $2 i l v E$ genes. To identify the $S$. meliloti genes involved in BCAA biosynthesis, we tested the auxotrophy or prototrophy of mutants of most of these genes on minimal medium supplemented or not with either isoleucine and valine or leucine. Mutants were either available from Tn5 mutant libraries in 2011 or 1021 S. meliloti strains (Milcamps et al. 1998; Pobigaylo et al. 2006) or constructed during the course of this study. The results of auxotrophy assays are listed in Table 1. Mutation in ilvI (SMc01431), which affects the first common step of the isoleucine and valine biosynthesis pathway, led to auxotrophy, whereas single mutants in ilvB1 (SMc02263), ilvB2 (SMb21530), and ilvG (SMc04455) were prototrophs. Mutation in ilvH (SMc01530), the only homologue of the regulatory subunit of the AHAS complex, was a prototroph, which is consistent with the fact

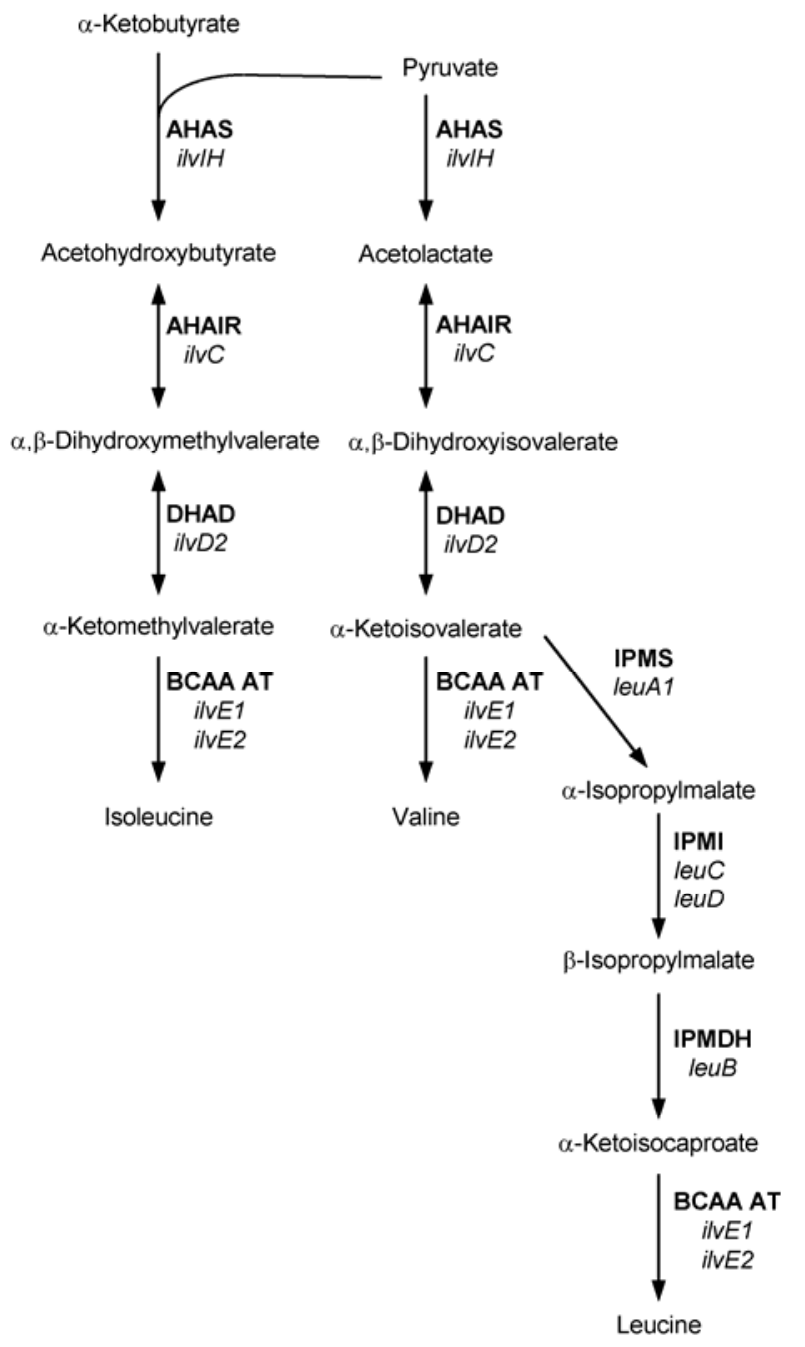

Fig. 1. Predicted branched-chain amino acid biosynthesis pathway in Sinorhizobium meliloti. The figure is adapted from Hassani and associates (2002). AHAS, acetohydroxy acid synthase; AHAIR, acetohydroxy acid isomeroreductase; DHAD, dihydroxy acid dehydratase; BCAA AT, branched-chain amino acid aminotransferase; IPMS, $\alpha$-isopropylmalate synthase; IPMI, $\alpha$-isopropylmalate isomerase; IPMDH, $\beta$-isopropylmalate dehydrogenase. $S$. meliloti genes involved in each enzymatic reaction are indicated based on auxotrophic mutations. The $i l v I H$ genes putatively form an operon. Mutations in $i l v I H, i l v C$, and $i l v D 2$ are prototrophic for leucine because $\alpha$-ketoisovalerate can be produced by IlvE from valine and 2oxoglutarate. 
that, in enterobacteria, IlvH has no enzymatic activity per se but is required for full IlvI activity as well as for the inhibition of IlvI activity by valine (Mendel et al. 2001). All the ilvD mutants, except ilvD2 (SMc04045), were prototrophs, indicating that only $i l v D 2$ is involved in the synthesis of isoleucine and valine. Similarly, a single mutation in the leuAl gene (SMc02117) led to leucine auxotrophy, indicating that the leuA2 copy (SMc02546) may not be required for the pathway. We did not obtain auxotrophic mutations affecting the BCAA aminotransferase IlvE, the last step of the BCAA biosynthesis pathway. The two single ilvE1 (SMc02896) and ilvE2 (SMc00042) mutants were prototrophs, suggesting that the two $i l v E$ copies may be functionally redundant.

\section{All auxotrophic mutations \\ in the BCAA biosynthetic pathway led to a defect in nodulation.}

We inoculated $M$. sativa plants with auxotrophic mutants that were affected in the different steps of the BCAA biosynthesis pathway and subsequently monitored nodule formation for approximately 40 days. Mutants were obtained from two closely related strains, 1021 and 2011 . We observed that all mutants exhibited a severe nodulation defect with, however, slight differences in phenotype between the two genetic backgrounds, 1021 and 2011 (Table 2). In strain 2011, nodules induced by $i l v I, i l v C$, ilvD2, leuAl, and leuB mutants appeared on roots approximately 20 days after those induced by the wild-type strain. The nodules formed did not fix nitrogen and cytological observations showed that these nodules were not invaded by bacteroids, although a few infection threads could be observed in the leucine auxotrophs 2011 leuAl and 2011 le $u B$ (not shown). In strain 1021, the phenotype observed for $i l v C$ and $i l v D 2$ was more pronounced than for ilvI, leuAl, $l e u B, l e u C$, and leuD because these two mutants exhibited a strong delay in nodulation (20 days after the wild-type strain) and the few nodules formed were mainly pseudonodules (root deformations such as bumps due to few cortical cell divisions) or abnormally developed nodules showing multiple or central vascular strands. None of these nodules or pseudonodules was invaded. Nodulation was also delayed in the $1021 \mathrm{ilvI}$, leuAl, $l e u B$, leuC, and leuD mutants but the delay was shorter than in strain 2011 (approximately 7 days after the wild-type strain). However, we observed that the symbiotic phenotypes of 1021 $i l v I, l e u A 1$, and leuD mutants were biased by the presence of a number of nitrogen-fixing nodules induced by mutant revertants. Isolation of bacteria from pink nodules showed that these nodules were invaded by prototrophic neomycin-sensitive bacteria. These mutants were constructed by plasmid insertions that revert at a higher frequency in plants, where they are not subjected to selection pressure, than the Tn5 mutations which are present in the other mutants (Table 1).

We concluded from this first set of plant tests that all mutations in the BCAA biosynthesis pathway led to a defect in nodulation in S. meliloti strains 2011 and 1021, contrary to what was previously shown for the $i l v D\left(\mathrm{Nod}^{+} \mathrm{Fix}^{+}\right)$, leuC/D, and leuB ( $\mathrm{Nod}^{+} \mathrm{Fix}^{-}$) mutants (Aguilar and Grasso 1991; Hassani et al. 2002). All the delayed nodules formed were not invaded and, therefore, displayed no nitrogen fixation.

\section{Addition of exogenous amino acids restored both prototrophy and nodulation in strain 2011.}

Addition of relevant amino acids (isoleucine and valine for ilv mutants or leucine for leu mutants) to the growth medium of $M$. sativa plants completely restored the nodulation ability of all 2011 auxotrophs (Table 2). In these conditions, mutantinduced nodules appeared at the same time as wild-typeinduced nodules or with a delay of only a few days. However, the nodules formed by ilv mutants in the presence of isoleucine and valine were not effective and cytological studies showed that, even though some infection threads were formed, nodule cells were not at all or only weakly invaded by bacteroids. This suggests that isoleucine and valine concentrations inside the plant cells may limit bacterial growth and, hence, the infection capacity of corresponding auxotrophs. In contrast, nodules induced by leu mutants in the presence of exogenous leucine were invaded in the normal way and fixed nitrogen, indicating that leucine may be provided by the plant to the bacteria during the infection process as well as in the symbiosome.

\section{Strains 2011 and 1021 behaved differently with respect to the symbiotic phenotype of ilvC and ilvD2 mutants.}

Supplementation experiments performed with 1021 auxotrophs showed that the nodulation ability of $i l v I, \operatorname{leuA} 1, \operatorname{leuB}$, $l e u C$, and leuD strains could be fully restored by addition of exogenous amino acids in a way similar to that observed with 2011 mutants. In contrast, the nodulation ability of the ilvD2 mutant was only partially rescued by addition of isoleucine and valine and no effect was observed on the nodulation ability of $i l v C$ when isoleucine and valine were added to the plant growth medium (Fig. 2). In the presence of isoleucine and valine, nodules induced by the 1021 ilvD2 mutant appeared with a marked delay (approximately 10 days) compared with wild-type nodules. These nodules were devoid of bacteria and, thus, ineffective. In the case of the $1021 \mathrm{ilv} C$ mutant, very few nodules were formed even in the presence of amino acids and most were only pseudonodules (cortical cell divisions that were not invaded), as in the absence of exogenous amino acids. Cytological observations of roots inoculated with the 1021 $i l v C$ and $i l v D 2$ strains in the presence of amino acids showed some root hair curling and the formation of very few infection threads that aborted rapidly (not shown).

In order to rule out the possible occurrence of secondary mutations affecting nodulation in these two strains, we complemented the $1021 i l v C$ and 1021 ilvD2 mutants with the wild-type $i l v C$ and $i l v D 2$ genes constitutively expressed in trans from a plasmid. Complementation of the $1021 \mathrm{ilvC}$ and $1021 \mathrm{ilvD} 2$ mutants fully restored the prototrophy, nodulation, and nitrogen-fixing abilities of these strains (Fig. 2).

To try to understand the phenotypic difference between the 1021 and $2011 i l v C$ and $i l v D 2$ mutants, we compared the growth rates of the four mutants in minimal medium liquid cultures containing different isoleucine and valine concentrations $(0.04,0.4$, and $0.8 \mathrm{mM})$. Because the growth rates of mutants were similar between the two genetic backgrounds (data not shown), we inferred that the $1021 i l v C$ and ilvD2 nodulation behavior was not due to a less efficient import of BCAA in strain 1021.

We also ruled out the possibility that the mutation itself could account for the phenotypic difference between the 1021 $i l v C$ (GMI11498) and 2011 ilvC (GMI11523) by reconstructing the same $i l v C$ mutation (Tn5 insertion $744 \mathrm{bp}$ after the start codon) using the pQB2 plasmid in the 2011 genetic background (strain GMI11544). The nodulation ability of this strain was fully restored by addition of isoleucine and valine into the plant growth medium like the former 2011 ilvC (GMI11523) mutant (data not shown).

\section{Nod factor production}

in the ilvC and ilvD2 mutants was not affected.

Two mutations that led to BCAA auxotrophy, ilvC and leuAl, have previously been shown to have impaired nodulation gene expression in S. meliloti (Lopez et al. 2001; Sanjuan-Pinilla et al. 2002). We wanted to know whether all auxotrophic mutations in the BCAA biosynthesis pathway were similarly impaired for 
nodulation gene expression. Consequently, we assessed the expression of the key nodulation gene, nod $C$, in the absence and presence of the plant inducer luteolin in the 1021 and 2011 auxotrophs overexpressing the nod gene activator NodD1 on the pRmM57 plasmid (Mulligan and Long 1989). NodC expression was determined by measuring $\beta$-galactosidase activity of the nodC-lac $Z$ translational fusion also carried by the pRmM57 plasmid (Table 3). In these experiments, auxotrophic strains were cultured in the presence of $0.8 \mathrm{mM}$ isoleucine, valine, or leucine to allow normal growth of the strains.

Again, strains 1021 and 2011 behaved differently with respect to nod gene expression. Previous work demonstrated that nod gene expression in the presence of luteolin is higher in strain 1021 than in strain 2011, probably due to a different amount of

Table 1. Bacterial (Sinorhizobium meliloti) strains and plasmids

\begin{tabular}{|c|c|c|c|}
\hline Strains, plasmids & Description $^{a}$ & Auxotrophy & Reference \\
\hline \multicolumn{4}{|l|}{ Strains } \\
\hline GMI11495 & 2011, Str $^{\mathrm{r}}$ derivative of 2011 & $\ldots$ & J. Dénarié \\
\hline GMI11496 & $1021, \mathrm{Str}^{\mathrm{r}}$ derivative of 2011 & $\ldots$ & Meade et al. 1982 \\
\hline GMI11497 & 1021 ilvB1::pVO155 (881 bp), Str $^{\mathrm{r}}, \mathrm{Neo}^{\mathrm{r}}$ & $\ldots$ & This work \\
\hline GMI11498 & 1021 ilvC::Tn5 (744 bp), Str $^{r}, \mathrm{Neo}^{\mathrm{r}}$ & Ile, Val & This work \\
\hline GMI11499 & 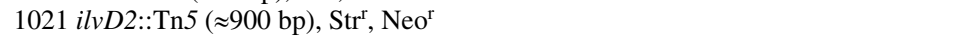 & Ile, Val & This work \\
\hline GMI11500 & 1021 ilvE1::pVO155 (491 bp), Str $^{\mathrm{r}}, \mathrm{Neo}^{\mathrm{r}}$ & $\ldots$ & This work \\
\hline GMI11501 & 1021 ilvH::Tn5-luxAB (167 bp), Str $^{\mathrm{r}}, \mathrm{Neo}^{\mathrm{r}}$ & $\ldots$ & Milcamps et al. 1998 \\
\hline GMI11502 & 1021 ilvI::pVO155 (962 bp), Str $^{\mathrm{r}}, \mathrm{Neo}^{\mathrm{r}}$ & Ile, Val & This work \\
\hline GMI11503 & 1021 leuA1::pVO155 (709 bp), Str $^{\mathrm{r}}, \mathrm{Neo}^{\mathrm{r}}$ & Leu & This work \\
\hline GMI11504 & 1021 leuB::Tn5-luxAB (372 bp), $\mathrm{Str}^{\mathrm{r}}, \mathrm{Neo}^{\mathrm{r}}$ & Leu & Milcamps et al. 1998 \\
\hline GMI11505 & 1021 leиC:: Tn5-luxAB (742 bp), Str $^{\mathrm{r}}, \mathrm{Neo}^{\mathrm{r}}$ & Leu & Milcamps et al. 1998 \\
\hline GMI11506 & 1021 leuD::pVO155 (324 bp), Str $^{\mathrm{r}}, \mathrm{Neo}^{\mathrm{r}}$ & Leu & This work \\
\hline GMI11507 & 1021 SMc04348::pVO155 (398 bp), Str $^{\mathrm{r}}, \mathrm{Neo}^{\mathrm{r}}$ & Ile, Val & This work \\
\hline GMI11508 & 1021 pGMI50122, Str $^{\mathrm{r}}, \mathrm{Gen}^{\mathrm{r}}$ & $\ldots$ & This work \\
\hline GMI11509 & GMI11498 pGMI50120, $\mathrm{Str}^{\mathrm{r}}, \mathrm{Neo}^{\mathrm{r}}, \mathrm{Gen}^{\mathrm{r}}$ & $\ldots$ & This work \\
\hline GMI11511 & GMI11499 pGMI50121, $\mathrm{Str}^{\mathrm{r}}, \mathrm{Neo}^{\mathrm{r}}, \mathrm{Gen}^{\mathrm{r}}$ & $\ldots$ & This work \\
\hline GMI11512 & GMI11507 pGMI50120, $\mathrm{Str}^{\mathrm{r}}, \mathrm{Neo}^{\mathrm{r}}, \mathrm{Gen}^{\mathrm{r}}$ & $\ldots$ & This work \\
\hline GMI11513 & GMI11507 pGMI50122, Str $^{r}, \mathrm{Neo}^{\mathrm{r}}, \mathrm{Gen}^{\mathrm{r}}$ & Ile, Val & This work \\
\hline GMI11540 & 1021 sitD::pK19mob2HMB $\Omega(844 \mathrm{bp}), \mathrm{Str}^{\mathrm{r}}, \mathrm{Neo}^{\mathrm{r}}$ & $\ldots$ & A. Becker \\
\hline GMI11541 & $1021 \mathrm{Tn} 5, \mathrm{Str}^{\mathrm{r}}, \mathrm{Neo}^{\mathrm{r}}$ & $\ldots$ & This work \\
\hline GMI11514 & 1021 pRmM57 & $\ldots$ & Capela et al. 2005 \\
\hline GMI11515 & GMI11498 pRmM57, Str $^{\mathrm{r}}, \mathrm{Neo}^{\mathrm{r}}$, Tet $^{\mathrm{r}}$ & Ile, Val & This work \\
\hline GMI11516 & GMI11499 pRmM57, Str $^{\mathrm{r}}, \mathrm{Neo}^{\mathrm{r}}, \mathrm{Tet}^{\mathrm{r}}$ & Ile, Val & This work \\
\hline GMI11517 & GMI11502 pRmM57, Str $^{\mathrm{r}}, \mathrm{Neo}^{\mathrm{r}}, \mathrm{Tet}^{\mathrm{r}}$ & Ile, Val & This work \\
\hline GMI11518 & GMI11503 pRmM57, Str $^{\mathrm{r}}, \mathrm{Neo}^{\mathrm{r}}, \mathrm{Tet}^{\mathrm{r}}$ & Leu & This work \\
\hline GMI11519 & GMI11504 pRmM57, Str $^{\mathrm{r}}, \mathrm{Neo}^{\mathrm{r}}, \mathrm{Tet}^{\mathrm{r}}$ & Leu & This work \\
\hline GMI11520 & GMI11505 pRmM57, Str $^{\mathrm{r}}, \mathrm{Neo}^{\mathrm{r}}, \mathrm{Tet}^{\mathrm{r}}$ & Leu & This work \\
\hline GMI11521 & GMI11506 pRmM57, Str $^{\mathrm{r}}, \mathrm{Neo}^{\mathrm{r}}, \mathrm{Tet}^{\mathrm{r}}$ & Leu & This work \\
\hline GMI11542 & GMI11540 pRmM57, Str $^{\mathrm{r}}, \mathrm{Neo}^{\mathrm{r}}, \mathrm{Tet}^{\mathrm{r}}$ & $\ldots$ & This work \\
\hline GMI11543 & GMI11541 pRmM57, Str $^{\mathrm{r}}, \mathrm{Neo}^{\mathrm{r}}, \mathrm{Tet}^{\mathrm{r}}$ & $\ldots$ & This work \\
\hline GMI11522 & 2011 ilvB2::mTn5 (693 bp), $\mathrm{Str}^{\mathrm{r}}, \mathrm{Neo}^{\mathrm{r}}$ & $\ldots$ & Pobigaylo et al. 2006 \\
\hline GMI11523 & 2011 ilvC::mTn5 (391 bp), Str $^{\mathrm{r}}, \mathrm{Neo}^{\mathrm{r}}$ & Ile, Val & Pobigaylo et al. 2006 \\
\hline GMI11524 & 2011 ilvD1::mTn5 (512 bp), Str $^{\mathrm{r}}, \mathrm{Neo}^{\mathrm{r}}$ & $\ldots$ & Pobigaylo et al. 2006 \\
\hline GMI11525 & 2011 ilvD2::mTn5 (583 bp), $\mathrm{Str}^{\mathrm{r}}, \mathrm{Neo}^{\mathrm{r}}$ & Ile, Val & Pobigaylo et al. 2006 \\
\hline GMI11526 & 2011 ilvD3::mTn5 (406 bp), Str ${ }^{\mathrm{r}}, \mathrm{Neo}^{\mathrm{r}}$ & $\ldots$ & Pobigaylo et al. 2006 \\
\hline GMI11527 & 2011 ilvD4::mTn5 (19 bp), Str $^{\mathrm{r}}, \mathrm{Neo}^{\mathrm{r}}$ & $\ldots$ & Pobigaylo et al. 2006 \\
\hline GMI11528 & 2011 ilvD5::mTn5 (931 bp), Str $^{\mathrm{r}}, \mathrm{Neo}^{\mathrm{r}}$ & $\ldots$ & Pobigaylo et al. 2006 \\
\hline GMI11529 & 2011 ilvE2::mTn5 (239 bp), Str $^{\mathrm{r}}, \mathrm{Neo}^{\mathrm{r}}$ & $\ldots$ & Pobigaylo et al. 2006 \\
\hline GMI11530 & $2011 i l v G:: \operatorname{mTn} 5$ (719 bp), $\mathrm{Str}^{\mathrm{r}}, \mathrm{Neo}^{\mathrm{r}}$ & $\ldots$ & Pobigaylo et al. 2006 \\
\hline GMI11531 & 2011 ilvI::mTn5 (966 bp), Str $^{\mathrm{r}}, \mathrm{Neo}^{\mathrm{r}}$ & Ile, Val & Pobigaylo et al. 2006 \\
\hline GMI11532 & 2011 leuA1::mTn5 (1379 bp), $\mathrm{Str}^{\mathrm{r}}, \mathrm{Neo}^{\mathrm{r}}$ & Leu & Pobigaylo et al. 2006 \\
\hline GMI11533 & 2011 leuB::mTn5 (765 bp), Str $^{r}, \mathrm{Neo}^{\mathrm{r}}$ & Leu & Pobigaylo et al. 2006 \\
\hline GMI11544 & 2011 ilvC::Tn5 (744 bp), Str $^{\mathrm{r}}, \mathrm{Neo}^{\mathrm{r}}$ & Ile, Val & This work \\
\hline GMI11534 & 2011 pRmM57 & $\ldots$ & This work \\
\hline GMI11535 & GMI11523 pRmM57, Str $^{\mathrm{r}}, \mathrm{Neo}^{\mathrm{r}}$, Tet $^{\mathrm{r}}$ & Ile, Val & This work \\
\hline GMI11536 & GMI11525 pRmM57, Str $^{\mathrm{r}}, \mathrm{Neo}^{\mathrm{r}}$, Tet $^{\mathrm{r}}$ & Ile, Val & This work \\
\hline GMI11537 & GMI11531 pRmM57, Str $^{\mathrm{r}}, \mathrm{Neo}^{\mathrm{r}}, \mathrm{Tet}^{\mathrm{r}}$ & Ile, Val & This work \\
\hline GMI11538 & GMI11532 pRmM57, Str $^{\mathrm{r}}, \mathrm{Neo}^{\mathrm{r}}, \mathrm{Tet}^{\mathrm{r}}$ & Leu & This work \\
\hline GMI11539 & GMI11533 pRmM57, Str $^{\mathrm{r}}, \mathrm{Neo}^{\mathrm{r}}, \mathrm{Tet}^{\mathrm{r}}$ & Leu & This work \\
\hline \multicolumn{4}{|l|}{ Plasmids } \\
\hline pBBR1MCS-5 & Cloning vector, Gen ${ }^{\mathrm{r}}$ & $\ldots$ & Kovach et al. 1995 \\
\hline pGMI50120 & pBBR1MCS-5 containing the $i l v C$ gene, $\mathrm{Gen}^{\mathrm{r}}$ & $\ldots$ & This work \\
\hline pGMI50121 & pBBR1MCS-5 containing the $i l v D 2, \mathrm{Gen}^{\mathrm{r}}$ & $\ldots$ & This work \\
\hline pGMI50122 & pBBR1MCS- 5 containing the SMc04348 gene, Gen ${ }^{\mathrm{r}}$ & $\ldots$ & This work \\
\hline $\mathrm{pK} 19 \mathrm{mob} 2 \mathrm{HMB} \Omega$ & Suicide plasmid, $\operatorname{Kan}^{\mathrm{r}}$ & $\ldots$ & A. Becker \\
\hline pMA6B & 7.5-kb EcoRI fragment from MA6-B (1021 ilvD2::Tn5) strain in pSUP102, $\mathrm{Neo}^{\mathrm{r}}, \mathrm{Tet}^{\mathrm{r}}$ & $\ldots$ & Grasso, unpublished \\
\hline pRmM57 & pSymA nod region, nodC-lacZ translational fusion, Tet $^{\mathrm{r}}$ & $\ldots$ & Mulligan and Long 1989 \\
\hline pRK600 & Helper plasmid, $\mathrm{Chl}^{\mathrm{r}}$ & $\ldots$ & Finan et al. 1986 \\
\hline pQB2 & 11-kb EcoRI fragment from strain 1028 (1021 ilvC::Tn5) in pSUP202, $\mathrm{Neo}^{\mathrm{r}}, \mathrm{Tet}^{\mathrm{r}}$ & $\ldots$ & Aguilar and Grasso 1991 \\
\hline pVO155 & Suicide plasmid, $\mathrm{Kan}^{\mathrm{r}}, \mathrm{Amp}^{\mathrm{r}}$ & $\ldots$ & Oke and Long 1999 \\
\hline pXLGD4 & hemA-lacZ translational fusion, Tet ${ }^{\mathrm{r}}$ & $\ldots$ & Leong et al. 1985 \\
\hline
\end{tabular}

\footnotetext{
${ }^{a}$ The location of the Tn5 and plasmid insertions from the start codon of genes are indicated in brackets. Str ${ }^{\mathrm{r}}=$ streptomycin resistance, Neo $^{\mathrm{r}}=$ neomycin

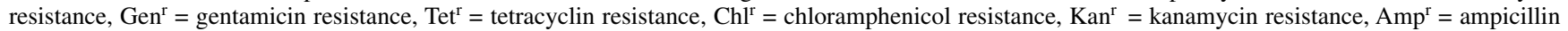
resistance, Ile $=$ isoleucine, Val $=$ valine, Leu $=$ leucine .
} 
active NodD proteins in the cells (Wais et al. 2002). Here, we confirmed that nod gene expression in the presence of luteolin is higher (approximately two- to threefold) in the 1021 wildtype strain than in the 2011 wild-type strain.

The ilvC mutants derived from both strains 1021 and 2011 presented a reduced level of $\beta$-galactosidase activity which reached approximately 66 and $50 \%$, respectively, of the level of the wild-type strains after $4 \mathrm{~h}$ of incubation with luteolin. However, these differences were no longer observed $24 \mathrm{~h}$ after induction, in contrast to previous work (Lopez et al. 2001). In addition, the $i l v D 2$ mutant derived from strain 2011 also displayed a significant reduction $(50 \%)$ in nodC induction by luteolin compared with the wild-type strain $4 \mathrm{~h}$ after addition of luteolin. Again, this reduction disappeared $24 \mathrm{~h}$ after induction.

Surprisingly, we observed that the nodC-lacZ translational fusion carried by the pRmM57 plasmid was highly susceptible to the presence of the antibiotic neomycin in the culture medium. Indeed, this fusion was no more inducible by luteolin when neomycin was added to the medium in all the neomycin-resistant mutant strains we tested, independently of the mutation itself (Supplementary Fig. S1A and B). Moreover, this defect was observed at the protein level ( $\beta$-galactosidase dosage of the nodC-lacZ translational fusion) but not at the RNA level (quantitative reverse-transcriptase polymerase chain reaction [qRT-PCR] experiments). In our experiments, the neomycin antibiotic was not added to the cultures of the mutants. To check if the $\beta$-galactosidase activities measured in these conditions for the mutants were not due to mutant revertants, we estimated the mutation reversion rate by counting prototroph colonies on minimal medium plates at the end of each experiment and found that it was $10^{-8}$ for the Tn5 mutants and $10^{-6}$ for the pVO155 plasmid insertion mutants.

In order to directly assess Nod factor production by the ilvC and ilvD2 mutants, we performed biochemical analyses of supernatants of 24-h luteolin-induced cultures from ilvC, ilvD2, and wild-type strains in the two genetic backgrounds, 1021 and 2011. Consistently with the $\beta$-galactosidase dosages performed $24 \mathrm{~h}$ after addition of luteolin, both $i l v C$ and $i l v D 2$ mutants were shown to produce Nod factors in similar quantity and of similar quality to the wild-type strains in both 1021 and 2011 backgrounds (Fig. 3).

From these results, we concluded that Nod factor biosynthesis is not the limiting factor that prevents nodulation of 1021 $i l v C$ and $1021 \mathrm{ilvD2}$ strains, at least in the presence of $0.8 \mathrm{mM}$ isoleucine and valine.
The TetR-type regulator SMc04348 adjacent to ilvC did not contribute to the symbiotic defect.

In order to assess the consequences of $i l v C$ and $i l v D 2$ inactivation on global gene expression in the $S$. meliloti strain 1021 , we analyzed the transcriptomes of these two mutants compared with the isogenic wild-type strain grown in minimal medium containing ammonium and succinate as nitrogen
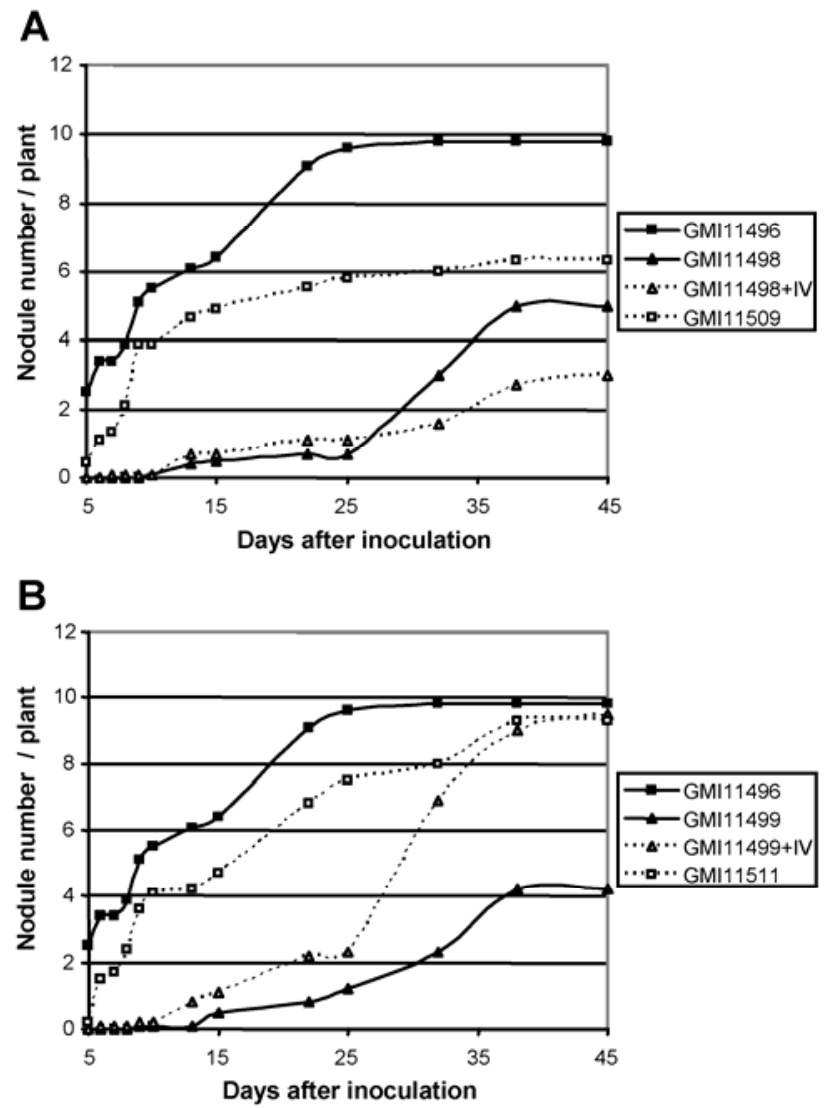

Fig. 2. Nodulation kinetics of the $1021 i l v C$ and $1021 i l v D 2$ auxotrophs and complemented strains. Results of a typical nodulation experiment. A, GMI11496: 1021 wild-type strain; GMI11498: 1021 ilvC mutant; GMI11509: $1021 i l v C$ complemented strain. The difference in the number of nodules between the wild type and the $1021 \mathrm{ilv} C$ complemented strains is not statistically significant. B, GMI11495: 2011 wild-type strain; GMI11499: 2011 ilvD2 mutant; GMI11511: 2011 ilvD2 complemented strain. IV: 0.2 $\mathrm{mM}$ isoleucine and valine were added to the plant growth medium.

Table 2. Symbiotic phenotype of auxotrophic mutants on Medicago sativa

\begin{tabular}{|c|c|c|c|c|c|}
\hline \multirow[b]{2}{*}{ Strains } & \multirow[b]{2}{*}{ Parental strain } & \multirow[b]{2}{*}{ Genotype } & \multirow[b]{2}{*}{ Auxotrophy } & \multicolumn{2}{|c|}{ Plant growth mediuma } \\
\hline & & & & Without amino acids & With amino acids \\
\hline GMI11531 & 2011 & $i l v I$ & Ile, Val & $\operatorname{Nod}^{D}$ (20 days) Fix ${ }^{-b}$ & $\mathrm{Nod}^{+} \mathrm{Fix}^{-}$ \\
\hline GMI11523 & 2011 & $i l v C$ & Ile, Val & $\operatorname{Nod}^{D}$ (20 days) Fix ${ }^{-b}$ & $\mathrm{Nod}^{+} \mathrm{Fix}^{-}$ \\
\hline GMI11525 & 2011 & $i l v D 2$ & Ile, Val & $\operatorname{Nod}^{D}$ (20 days) Fix ${ }^{-b}$ & $\mathrm{Nod}^{+} \mathrm{Fix}^{-}$ \\
\hline GMI11532 & 2011 & leuA1 & Leu & $\operatorname{Nod}^{\mathrm{D}}$ (20 days) Fix ${ }^{-b}$ & $\mathrm{Nod}^{+} \mathrm{Fix}^{ \pm}$ \\
\hline GMI11533 & 2011 & leuB & Leu & $\operatorname{Nod}^{D}$ (20 days) Fix ${ }^{-b}$ & $\operatorname{Nod}^{+} \mathrm{Fix}^{+}$ \\
\hline GMI11502 & 1021 & $i l v I$ & Ile, Val & $\operatorname{Nod}^{D}(7$ days $) F^{ \pm c}$ & $\operatorname{Nod}^{+} \mathrm{Fix}^{ \pm \mathrm{c}}$ \\
\hline GMI11498 & 1021 & $i l v C$ & Ile, Val & $\operatorname{Nod}^{\mathrm{D}}$ (20 days) Fix ${ }^{-b}$ & $\operatorname{Nod}^{\mathrm{D}}$ (20 days) Fix \\
\hline GMI11499 & 1021 & $i l v D 2$ & Ile, Val & $\operatorname{Nod}^{\mathrm{D}}$ (20 days) Fix ${ }^{-b}$ & $\operatorname{Nod}^{\mathrm{D}}$ (10 days) Fix \\
\hline GMI11503 & 1021 & leuAl & Leu & $\operatorname{Nod}^{\mathrm{D}}$ (7 days) Fix ${ }^{ \pm c}$ & $\mathrm{Nod}^{+} \mathrm{Fix}^{+}$ \\
\hline GMI11505 & 1021 & leuC & Leu & $\operatorname{Nod}^{\mathrm{D}}$ (7 days) Fix ${ }^{-}$ & $\mathrm{Nod}^{+} \mathrm{Fix}^{+}$ \\
\hline GMI11506 & 1021 & leuD & Leu & $\operatorname{Nod}^{D}$ (7 days) Fix ${ }^{ \pm c}$ & $\mathrm{Nod}^{+} \mathrm{Fix}^{+}$ \\
\hline GMI11504 & 1021 & leuB & Leu & $\operatorname{Nod}^{\mathrm{D}}$ (7 days) Fix ${ }^{-}$ & $\mathrm{Nod}^{+} \mathrm{Fix}^{+}$ \\
\hline
\end{tabular}

${ }^{a}$ Nodulation phenotypes were determined in the absence or presence of $0.2 \mathrm{mM}$ of the missing amino acids in the plant growth medium. Nod ${ }^{\mathrm{D}}=$ nodulation delayed, $\mathrm{Nod}^{+}=$wild type nodulation kinetics, Fix ${ }^{+}=$nitrogen-fixing nodules, Fix ${ }^{-}=$non-nitrogen-fixing nodules, Fix ${ }^{ \pm}=$partial impairment of nitrogen fixation. The number of days of delay before nodulation compared with the wild-type strains was averaged from at least three independent experiments.

b Number of induced nodules was low.

c Pink nitrogen-fixing nodules were due to mutant revertants. 
and carbon sources and supplemented with isoleucine and valine. We found very few genes whose expression varied between mutants and the wild type (not shown). Among them, only one gene, SMc04348, was consistently induced in the $i l v C$ and ilvD2 mutants. SMc04348 encodes a TetR-type regulator and is located immediately upstream from the $i l v C$ gene in the genome. We validated the induction of this gene by qRT-PCR in the two mutants (Supplementary Fig. S2A). We wanted to know whether overexpression of SMc04348 could affect the symbiotic properties of the wild-type strain. Consequently, we constructed a strain (GMI11508) overexpressing the TetR reguator SMc04348 on a plasmid and tested its symbiotic performances on $M$. sativa. We found that overexpression of SMc04348 in strain 1021 influenced neither the nodulation nor the nitrogen-fixation ability of the strain. We also constructed a SMc04348 null mutant by plasmid insertion (GMI11507). The 1021 SMc04348 mutant was auxotrophic for isoleucine and valine, like the ilvC mutant, and displayed the same nodulation phenotype as the 1021 $i l v C$ strain. We showed that the auxotrophy and the nodulation phenotype of this strain was due to the polarity of the SMc04348 mutation on the $i l v C$ gene because in trans expression of ilvC on a plasmid (GMI11512) restored both the prototrophy and the nodulation ability of the SMc04348 mutant whereas in trans expression of SMc04348 on a plasmid (GMI11513) did not reverse the phenotype.

Table 3. Expression of nodC in auxotrophic mutants

\begin{tabular}{|c|c|c|c|c|c|}
\hline \multirow[b]{2}{*}{ Strains } & \multirow[b]{2}{*}{ Parental strain } & \multirow[b]{2}{*}{ Genotype } & \multicolumn{3}{|c|}{$\beta$-Galactosidase activity ${ }^{a}$} \\
\hline & & & -Lut & +Lut $(4 \mathrm{~h})$ & + Lut $(24$ h) \\
\hline GMI11534 & 2011 & Wild type & $20 \pm 1$ & $472 \pm 70$ & $251 \pm 40$ \\
\hline GMI1 1537 & 2011 & $i l v I$ & $21 \pm 2$ & $352 \pm 63$ & nd \\
\hline GMI11535 & 2011 & $i l v C$ & $15 \pm 2$ & $204 \pm 38^{*}$ & $266 \pm 56$ \\
\hline GMI11536 & 2011 & ilvD2 & $15 \pm 1$ & $233 \pm 24 *$ & $256 \pm 30$ \\
\hline GMI1 1538 & 2011 & lеиAl & $20 \pm 1$ & $452 \pm 10$ & nd \\
\hline GMI1 1539 & 2011 & leuB & $15 \pm 1$ & $361 \pm 54$ & nd \\
\hline GMI11514 & 1021 & Wild type & $27 \pm 1$ & $1,254 \pm 93$ & $785 \pm 71$ \\
\hline GMI1 1517 & 1021 & $i l v I$ & $27 \pm 1$ & $1,415 \pm 94$ & nd \\
\hline GMI11515 & 1021 & $i l v C$ & $22 \pm 5$ & $834 \pm 75^{*}$ & $1,074 \pm 232$ \\
\hline GMI11516 & 1021 & $i l v D 2$ & $26 \pm 2$ & $1,287 \pm 74$ & nd \\
\hline GMI11518 & 1021 & leuAl & $34 \pm 3$ & $1,328 \pm 125$ & nd \\
\hline GMI11520 & 1021 & leuC & $28 \pm 1$ & $1,183 \pm 67$ & nd \\
\hline GMI11521 & 1021 & leuD & $24 \pm 2$ & $971 \pm 83^{*}$ & nd \\
\hline GMI11519 & 1021 & leuB & $29 \pm 4$ & $1,048 \pm 197$ & nd \\
\hline
\end{tabular}

${ }^{a} \beta$-Galactosidase activities were measured in Miller units in the absence or presence of $10 \mu \mathrm{M}$ luteolin over a period of 4 or $24 \mathrm{~h}$. Average results and standard deviation of three independent experiments are indicated. An asterisk $\left(^{*}\right)$ indicates that the difference between the mutant and the wild type was statistically significant $(t$ test, $P<0.05)$; nd $=$ not determined.
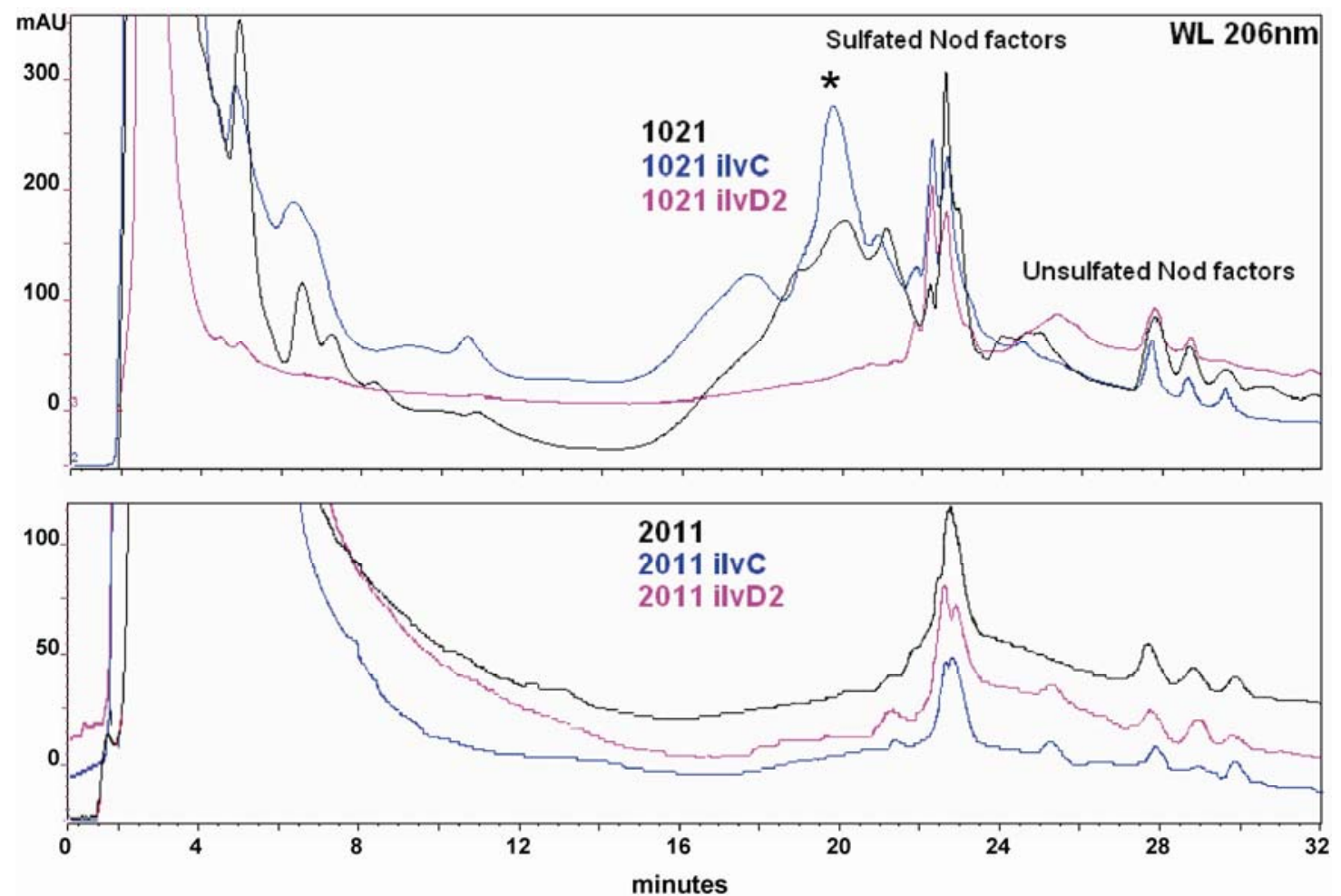

Fig. 3. Nod factor production in the $i l v C$ and $i l v D 2$ mutants and in the respective wild-type strains. High-performance liquid chromatography UV traces recorded at $206 \mathrm{~nm}$ of the XAD extract eluted with 50\% acetonitrile/water fraction and injected on an Xterra reversed-phase column. A, 1021 ilvC (blue), 1021 $i l v D 2$ (pink), and 1021 wild type (black). B, $2011 \mathrm{ilvC}$ (blue), $2011 \mathrm{ilvD2}$ (pink), and 2011 wild type (black). Asterisk (*) indicates low molecular weight polyethylene glycol present in water of cultures that were enriched during extraction. 


\section{DISCUSSION}

Apart from studies on mutants in the nodulation genes, reports in the literature on rhizobial mutants that are completely deficient in nodulation are rare. However, three independent studies reported several $S$. meliloti mutants which were defective in host legume nodulation and unable to synthesize the BCAA isoleucine, valine, and leucine. This led us to reexamine the role in nodulation of this biosynthesis pathway as a whole in S. meliloti.

Based on the E. coli biosynthesis pathway model, we searched for homologous ilv and leu genes on the $S$. meliloti genome and checked their requirement for the synthesis of isoleucine, valine, and leucine by auxotrophy tests of mutants of these genes. These assays enabled the reconstruction of most of the biosynthesis pathway in S. meliloti. Only one AHAS isozyme was identified, the AHAS isozyme III (IlvIH) ubiquitously found in bacteria, whereas two BCAA aminotransferases (IlvE1 and IlvE2) catalyzing the last step of the pathway may be functional in S. meliloti.

Here, we characterized the symbiotic phenotype of three mutants auxotrophic for isoleucine and valine $(i l v I, i l v C$, and $i l v D 2)$ and four mutants auxotrophic for leucine $(l e u A 1$, leuC, $l e u D$, and $l e u B$ ) in two closely related $S$. meliloti strains, 1021 and 2011. We found that all auxotrophic mutants in both strains presented a similar phenotype on plants in the absence of amino acids. Indeed, the mutants were severely deficient in their nodulation and infection abilities on $M$. sativa host plants. Nodules were formed after a delay of several days compared with nodules induced by the wild-type strains, and were few in number, often abnormally developed and not invaded by bacteria. These results indicate that BCAA are essential for both nodulation and infection in S. meliloti.

Unexpectedly, we also observed that the nodulation deficiency of most ilv and leu mutants was essentially restored by addition of BCAA to the plant growth medium. For restoration to be successful, amino acids had to be added to the plant culture medium and not to the inoculum itself. Other than the noticeable exceptions of the $i l v C$ and ilvD2 mutants in the 1021 background, our results demonstrated that the nodulation deficiency of the mutants was entirely linked to their auxotrophy. This suggests that the concentration of BCAA in alfalfa root exudates is limiting and does not satisfy the requirements for the normal metabolic activity of isoleucine, valine, and leucine auxotrophs. However, unlike leucine auxotrophs, supplementation with exogenous amino acids restored neither the nitrogen fixation nor the normal infection process in isoleucine and valine auxotrophs. Therefore, isoleucine and valine amino acids may also be limiting inside the alfalfa root tissues.

Some of our data confirmed results obtained in previous studies while other data disagreed. We confirmed that supplementation with amino acids does not restore the symbiotic phenotype of the $i l v C$ mutant in strain 1021 although the $i l v C$ nodulation phenotype is background dependent. We also confirmed that the 1021 leuAl mutant can nodulate alfalfa in the presence of leucine. One striking discrepancy between our results and previous studies mainly concerns the ilvD2 phenotype. Although this mutant was found to be symbiotically effective in two independent studies in strains 1021 and Rmd201 (Aguilar and Grasso 1991; Hassani et al. 2002), our ilvD2 mutants in strains 1021 and 2011 were strongly impaired for nodulation even in the presence of amino acids in strain 1021. Very recently, Pobigaylo and associates (2008) confirmed the nodulation phenotype of the 2011 ilvD2 mutant using the same strain as the one used in this study.

Another major difference between our study and previous studies was the ability to produce Nod factors by the ilv and leu auxotrophs. In our study, we found that all auxotrophic strains were able to induce a nodC-lacZ fusion, contrary to previous works on the $i l v C$ and leuAl mutants (Aguilar and Grasso 1991; Sanjuan-Pinilla et al. 2002). We only observed a partial reduction of nodC-lacZ expression in the $i l v C$ and ilvD2 mutants a few hours after incubation with luteolin. However, this reduction disappeared after a longer incubation with luteolin. In addition, we demonstrated by biochemical analyses that the 1021 and $2011 i l v C$ mutants normally produce Nod factors in 24-h luteolin-induced cultures. Interestingly, we found that the nodC-lacZ translational fusion carried by the pRmM57 plasmid was very weakly expressed at the protein level in the presence of neomycin in the culture medium even upon induction by luteolin. Neomycin blocks translation initiation; therefore, we suspect that the translation of the nodC mRNA is particularly sensitive to this mechanism even in strains that are resistant to this antibiotic. This sensitivity could explain results reported by Aguilar and Grasso (1991) and Sanjuan-Pinilla and associates (2002) concerning the lack of expression of this fusion in the neomycin-resistant $i l v C$ and leuA1 mutants. Our nod gene induction and Nod factor production assays clearly demonstrated that the irreversibility of the nodulation phenotype of the 1021 ilvC and ilvD2 auxotrophs by supplementation with amino acids was not due to a defect in Nod factor synthesis.

In this study, we found that the $i l v C$ and $i l v D 2$ mutations had an impact on nodulation which depended on the genetic background of the strain. Although the S. meliloti 1021 and 2011 strains are very close to each other, because they are two independent spontaneous streptomycin-resistant derivatives of the same parental strain, they display many genetic differences and many phenotypic differences. Differences include nod gene induction level by NodD1 and luteolin and the calciumspiking kinetic response in host plants (Wais et al. 2002), the nitrogen fixation efficiency on some ecotypes of $M$. truncatula (Terpolilli et al. 2008), their ability to form biofilms (Fujishige et al. 2006), and the differential expression of hundreds of genes, including phosphate starvation responsive genes (Krol and Becker 2004; personal observation). The symbiotic phenotype of $i l v C$ and $i l v D 2$ mutants is possibly another difference between the two strains. Alternatively, we cannot exclude that secondary mutations have been selected during the construction of these two particular mutants in strain 1021, either because strain 1021 is more mutator than strain 2011 or because BCAA biosynthesis genes are essential genes of central metabolism, or both.

Preliminary analyses of the $1021 \mathrm{ilvC}$ and $1021 \mathrm{ilvD} 2$ transcriptomes in free-living cultures did not provide any clues regarding genes deregulated in these mutants that may be involved in their symbiotic defect. We investigated the role of the TetRtype transcription regulator SMc04348, located upstream from $i l v C$ on the genome, whose expression was found to be higher in both mutants than in the wild-type strain. Induction of this gene in the mutants was observed in both 1021 and 2011 genetic backgrounds. However, we found that the level of expression of SMc04348 in the mutants depended on the source of nitrogen in the culture medium, expression of this gene being higher in the presence of $15 \mathrm{mM}$ ammonia than in the presence of $6 \mathrm{mM}$ glutamate, suggesting that this regulator may connect BCAA biosynthesis and nitrogen metabolism. SMc04348 was found to be linked to ilvC in the genome of several $\alpha$ proteobacteria such as Rhizobium etli, Mesorhizobium loti, Agrobacterium tumefaciens or Brucella spp. This conserved synteny suggests that the regulator may, thus, be functionally linked to $i l v C$ or to the isoleucine and valine biosynthetic pathway, although we do not have further evidence for this. Preliminary transcriptome analyses of strains overexpressing SMc04348 or inactivated in SMc04348 
cultivated in minimal medium did not help identify the SMc04348 target genes (not shown). Thus, the role of this regulator remains unknown. The characterization of the symbiotic phenotypes of the SMc04348 overexpressing strain (GMI11508) and the SMc04348 mutant strains (GMI11507 and GMI11512) indicated that this gene does not play an essential role in the nodulation process in S. meliloti.

In rhizobia, isoleucine, valine, or leucine auxotrophic mutations do not always lead to a nodulation defect. For example, leucine auxotrophs of Bradyrhizobium japonicum form effective nodules on soybean (Kummer and Kuykendall 1989). In contrast, auxotrophic mutations in leucine biosynthesis genes prevent nodulation of photosynthetic Bradyrhizobium spp. whose genomes lack classical nod genes. In the same photosynthetic Bradyrhizobium spp., other auxotrophic mutations (in particular, for proline amino acid) also lead to a nodulation defect on Aeschynomene host plants. In the two latter cases, the phenotype was rescued by addition of the missing amino acids to the plant nutrient medium (Giraud et al. 2007). Taken together, these data and our results indicate that the nodulation phenotype of auxotrophic mutants in rhizobia is likely determined by the availability of amino acids and their derivatives in the root exudates. Hosts with different profiles of exudates may explain the different impacts of rhizobial auxotrophy on the symbiotic interaction. In natural environments, the intrinsic metabolic capacity of rhizobia to synthesize amino acids, which may be limiting in the rhizosphere of their host plants, is essential for both the establishment of an effective symbiosis and their competitiveness.

In conclusion, we believe that this work clarifies the role of the BCAA biosynthesis in the nodulation process of $S$. meliloti. Indeed, we have shown that all mutations that are auxotrophic for BCAA lead to a severe nodulation defect on $M$. sativa host plants, demonstrating that the entire biosynthesis pathway is necessary for nodulation. We also demonstrated that auxotrophy is likely the primary cause of the nodulation defect in most of these mutants. However, the nodulation defect of two noticeable auxotroph mutants, $i l v C$ and $i l v D 2$ in the specific 1021 genetic background, remains to be elucidated.

\section{MATERIALS AND METHODS}

\section{Bacterial strains and growth conditions.}

Bacterial strains and plasmids used in this study are listed in Table 1. Auxotrophic strains were grown either in rich medium (Luria-Bertani [LB] with $2.5 \mathrm{mM} \mathrm{CaCl}_{2}$ and $2.5 \mathrm{mM} \mathrm{MgSO}_{4}$ ) or in Vincent minimal medium modified as previously described (Becker et al. 2004) supplemented with isoleucine and valine or leucine at a final concentration of $0.8 \mathrm{mM}$. The concentrations of antibiotics used for $S$. meliloti cultures were 200 $\mu \mathrm{g} / \mathrm{ml}$ for streptomycin, $100 \mu \mathrm{g} / \mathrm{ml}$ for neomycin, $10 \mu \mathrm{g} / \mathrm{ml}$ for tetracycline, and $30 \mu \mathrm{g} / \mathrm{ml}$ for gentamycin.

\section{Constructions of strains and plasmids.}

All S. meliloti 2011 mTn5 mutants were obtained from the mTn5 random mutant library (Pobigaylo et al. 2006). The $S$. meliloti $1021 \mathrm{ilvH}$, leuB, and leuC mutants were obtained from a Tn5 random mutant library (Milcamps et al. 1998). The 2011 ilvC (GMI11544), 1021 ilvC (GMI11498), and 1021 ilvD2 (GMI11499) mutants were constructed by site-specific mutagenesis using the suicide plasmids pQB2 and pMA6B carrying an $i l v C:: \operatorname{Tn} 5$ and $i l v D 2:: \operatorname{Tn} 5$ cassette, respectively (Aguilar and Grasso 1991). Both plasmids were transferred to S. meliloti by biparental conjugation using E. coli $\mathrm{S} 17-1$ as donor strain. The double event of recombination was selected by searching for tetracycline-sensitive streptomycin- and neomycin-resistant colonies. The mutants were then checked by both Southern blot and PCR analyses. The prototrophic 1021 Tn5 (GMI11541) mutant was obtained by a nonspecific Tn 5 insertion from the pMA6B plasmid. The $1021 i l v B 1$, ilvI, leuAl, and leuD mutants were constructed by site-specific insertion mutagenesis using the nonreplicative plasmid pVO155. The pVO155 plasmid was digested by BamHI and XbaI. A DNA fragment of each gene to be inactivated was amplified by PCR with primers containing a

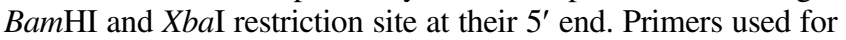
mutagenesis are listed in Supplementary Table S2. The PCR products were digested with BamHI and $X b a \mathrm{I}$, ligated to the pVO155 plasmid, and transformed into DH5 $\alpha$ E. coli-competent cells. The plasmid constructions were checked by sequencing and then conjugating into $S$. meliloti strain 1021 using the pRK600 as helper plasmid. Transconjugants were selected three times on $\mathrm{LB}$ plates containing $2.5 \mathrm{mM} \mathrm{CaCl}_{2}, 2.5 \mathrm{mM} \mathrm{MgSO}_{4}$, streptomycin at $200 \mu \mathrm{g} / \mathrm{ml}$, and neomycin at $100 \mu \mathrm{g} / \mathrm{ml}$. Correct plasmid integration was checked by Southern blot analysis.

For the construction of the complementation plasmids pGMI50120 (ilvC), pGMI50121 (ilvD2), and pGMI50122 (SMc04348), the wild-type ilvC, ilvD2, and SMc04348 genes were amplified by PCR using $S$. meliloti 1021 genomic DNA as template and ODC161-ODC162, ODC163-ODC164, and OCD177-ODC178 primer pairs, respectively, which carry a $X b a \mathrm{I}$ and Bam HI restriction site at their $5^{\prime}$ end (Table S2). The three fragments were digested with $B a m \mathrm{HI}$ and $X b a \mathrm{I}$ and ligated into a BamHI-XbaI-digested pBBR1MCS-5 plasmid. The resulting plasmids were transformed into $E$. coli $\mathrm{DH} 5 \alpha-$ competent cells. Clones were screened by PCR and checked by DNA sequencing prior to introduction into $S$. meliloti ilvC, $i l v D 2$, and SMc04348 auxotrophic mutants by triparental mating using the pRK600 as helper plasmid.

The pXLGD4 and pRmM57 replicative plasmids were introduced into all auxotrophs and wild-type strains by triparental mating using the pRK600 as helper plasmid.

\section{Plant assays.}

Seed of Medicago sativa cv. Europe were surface sterilized, germinated, and allowed to grown in $12-\mathrm{cm}^{2}$ plates containing slanting nitrogen-free Fahraeus agar medium for 3 days at $22^{\circ} \mathrm{C}$ with day and night cycles of 16 and $8 \mathrm{~h}$, respectively. The plants were then inoculated with $2 \times 10^{3}$ bacteria/plant. For supplementation experiments, either isoleucine and valine or leucine were added to the plant medium at $0.2 \mathrm{mM}$ because higher amino acid concentrations inhibited the growth of plant roots. Nodulation kinetics were monitored for approximately 40 days.

\section{Cytological studies.}

For cytological observations, plants were inoculated with strains carrying the pXLGD4 plasmid that expresses the hemAlac $Z$ fusion at a constitutive level. For observations at early stages, entire roots were collected 7 days after inoculation, fixed with $2 \%$ glutaraldehyde solution for $1.5 \mathrm{~h}$ under vacuum, rinsed three times in $\mathrm{Z}^{\prime}$ buffer $(0.1 \mathrm{M}$ potassium phosphate buffer, $\mathrm{pH} 7.4,1 \mathrm{mM} \mathrm{MgSO}$, and $10 \mathrm{mM} \mathrm{KCl}$ ), and stained overnight at $37^{\circ} \mathrm{C}$ in $\mathrm{Z}^{\prime}$ buffer containing $0.08 \% \mathrm{X}$-gal (5bromo-4-chloro-3-indolyl- $\beta$-D-galactoside), $5 \mathrm{mM} \mathrm{K}_{3} \mathrm{Fe}(\mathrm{CN})_{6}$, and $5 \mathrm{mM} \mathrm{K}_{4} \mathrm{Fe}(\mathrm{CN})_{6}$. For observations at late stages, 35-dayold nodules were harvested, fixed with $2 \%$ glutaradehyde in $\mathrm{Z}^{\prime}$ buffer, and then sliced into $80-\mu \mathrm{m}$-thick longitudinal sections using a vibrating-blade microtom (Leica VT1000S, Heidelberg, Germany) before staining. Entire roots or cut nodules were observed with an optical microscope.

\section{nodC gene induction assays.}

S. meliloti strains carrying the pRmM57 plasmid were grown at $28^{\circ} \mathrm{C}$ in Vincent minimal medium containing $6 \mathrm{mM}$ glutamate as sole nitrogen source and $0.8 \mathrm{mM}$ isoleucine and 
valine or leucine. Cultures were diluted in fresh medium at an optical density at $600 \mathrm{~nm}$ of 0.08 and left to grow for $3 \mathrm{~h}$. The cultures were then incubated with or without $10 \mu \mathrm{M}$ luteolin (Sigma) for 4 or 24 more hours. $\beta$-Galactosidase activities were measured using $0.5 \mathrm{ml}$ of culture as previously described (Miller 1972).

\section{Nod factor production.}

S. meliloti strains carrying the pRmM57 plasmid were grown at $28^{\circ} \mathrm{C}$ in Vincent minimal medium containing $6 \mathrm{mM}$ glutamate as sole nitrogen source and $0.8 \mathrm{mM}$ isoleucine and valine or leucine. Cultures were diluted in fresh medium at an optical density at $600 \mathrm{~nm}$ of 0.1 in the presence of $10 \mu \mathrm{M}$ luteolin (Sigma) and grown for $24 \mathrm{~h}$. The cultures were then centrifuged and supernatants were stored at $4{ }^{\circ} \mathrm{C}$ until analyses.

Nod factors were extracted from filtered culture supernatants by XAD4 bed adsorption (50 g of phase per liter). After $2 \mathrm{~h}$ of stirring, the bed was retained by filtration and washed with pure water. Nod factors were eluted using a $50 \%$ water/acetonitrile solution $(200 \mathrm{ml})$. Purification was performed on a highperformance liquid chromatography (HPLC) system Dionex P680-170U (Dionex Corporation, Sunnyvale, CA, U.S.A.) with a narrowbore analytical C18 reverse-phase column (2.1 by 150 $\mathrm{mm}, 3.5 \mu \mathrm{m}$; Xterra, Waters, Milford, MA, U.S.A.) for $8 \mathrm{~min}$ in isocratic solvent A (water/acetonitrile, 80:20 [vol/vol]), followed by linear gradient for $25 \mathrm{~min}$ from solvent A to solvent B (100\% acetonitrile) and another isocratic step at $100 \%$ acetonitrile for $5 \mathrm{~min}$. The return to the initial condition occurred within $10 \mathrm{~min}$ and an equilibration time of $10 \mathrm{~min}$ was necessary. The flow rate was of $0.2 \mathrm{ml} \mathrm{min}^{-1}$ and the UV absorption was monitored at $206 \mathrm{~nm}$.

The XAD extracts were dried under a nitrogen flux and redissolved in $500 \mu \mathrm{l}$ of 80:20 water/acetonitrile solution and 10 $\mu \mathrm{l}$ was injected on the HPLC column.

Each HPLC fraction produced was analyzed using an ESIQqToF Ultima apparatus (Waters) using direct infusion. Spectra were recorded in both the positive and negative mode. Peaks detected in the expected molecular weight range $(\mathrm{m} / \mathrm{z}$ 1,000 to 1,500 for the simple charged species or 500 to 700 for the double-charged ones) were subjected to dual mass spectrometry (MS/MS) experiment to confirm their lipo-chito oligosaccharide nature and structure.

Energies were the following: probe, $3 \mathrm{kV}$; cone, $100 \mathrm{~V}$; Rf, $70 \mathrm{~V}$; and collision cell, $15 \mathrm{~V}$ for MS and $30 \mathrm{~V}$ for MS/MS. Collision gas was argon and direct inlet was solvent $\mathrm{AcCN} / \mathrm{H}_{2} \mathrm{O} 1: 1$ and $1 \%$ acetic acid; rate, $10 \mu \mathrm{min} \mathrm{m}^{-1}$. Concentrations were approximately $10^{-4} \mathrm{M}$, source temperature was $80^{\circ} \mathrm{C}$, and drying gas temperature was $120^{\circ} \mathrm{C}$.

\section{RNA preparation.}

Filtered bacteria were resuspended in $3 \mathrm{ml}$ of lysis solution (1.4\% sodium dodecyl sulfate, $4 \mathrm{mM}$ EDTA, and proteinase $\mathrm{K}$ at $0.4 \mathrm{mg} / \mathrm{ml}$ ) and incubated at $65^{\circ} \mathrm{C}$ for $20 \mathrm{~min}$. Proteins were precipitated by adding $1.5 \mathrm{ml}$ of $\mathrm{NaCl} 5 \mathrm{M}$ at $4^{\circ} \mathrm{C}$ for $10 \mathrm{~min}$. Nucleic acids were precipitated from the supernatant by addition of one volume of isopropanol and the pellet was resuspended in RNAse-free water. DNA was removed from RNA preparations using RNeasy columns (clean-up procedure with DNase I treatment) (Qiagen, Germany).

\section{Transcriptome analyses.}

RNA $(20 \mu \mathrm{g})$ was reverse transcribed using Superscript II reverse transcriptase (Invitrogen, Carlsbad, CA, U.S.A.) and random hexamers as primers. Cy3- and Cy5-labeled cDNAs were prepared according to DeRisi and associates (1997). The microarrays used in this study are described in Krol and Becker (2004) and were purchased from A. Becker (University of Bielefeld, Germany). Hybridizations were performed in DIG Easy Hyb buffer (Roche, Mannheim, Germany) in Corning chambers at $42^{\circ} \mathrm{C}$ for $16 \mathrm{~h}$. Data were acquired on a Genepix 4000 scanner (Axon Instruments, Foster City, CA, U.S.A.) and quantification of median signal was performed using Genepix pro 3.0 (Axon Instruments). Data analyses were carried out using Genesight 3.5 (Biodiscovery, Inc., El Segundo, CA, U.S.A.). At least two independent experiments were performed for each transcriptome comparison.

\section{qRT-PCR.}

Reverse transcriptions were performed from $1 \mu \mathrm{g}$ of RNA using Superscript II reverse transcriptase (Invitrogen) and random hexamers as primers. cDNAs were used for running realtime PCR on a LightCycler system (Roche) using the FastStart DNA Master ${ }^{\text {PLUS }}$ SYBRGreen I kit (Roche) according to the manufacturer's instructions. The rplM gene was used as reference gene for data normalization. Primers used are listed in Supplementary Table S3.

\section{ACKNOWLEDGMENTS}

We thank A. Becker (University of Bielefeld) and IIT GmbH (Bielefeld, Germany) for providing all the $S$. meliloti 2011 mTn5 mutants; and F. de Bruijn and L. Sauviac (Laboratoire Interactions Plantes Micro-Organismes Toulouse) for providing the S. meliloti $1021 \mathrm{ilvH}$, leuB, and leuC Tn5 mutants. The work was supported by the France-Argentina ECOS-Sud program (A04B01).

\section{LITERATURE CITED}

Aguilar, O. M., and Grasso, D. H. 1991. The product of the Rhizobium meliloti ilvC gene is required for isoleucine and valine synthesis and nodulation of alfalfa. J. Bacteriol. 173:7756-7764.

Ardourel, M., Lortet, G., Maillet, F., Roche, P., Truchet, G., Promé, J. C., and Rosenberg, C. 1995. In Rhizobium meliloti, the operon associated with the nod box n5 comprises nodL, noeA and noeB, three host-range genes specifically required for the nodulation of particular Medicago species. Mol. Microbiol. 17:687-699.

Becker, A., Berges, H., Krol, E., Bruand, C., Ruberg, S., Capela, D., Lauber, E., Meilhoc, E., Ampe, F., de Bruijn, F. J., Fourment, J., Francez-Charlot, A., Kahn, D., Kuster, H., Liebe, C., Puhler, A., Weidner, S., and Batut, J. 2004. Global changes in gene expression in Sinorhizobium meliloti 1021 under microoxic and symbiotic conditions. Mol. Plant-Microbe Interact. 17:292-303.

Capela, D., Carrere, S., and Batut, J. 2005. Transcriptome-based identification of the NodD1 regulon of Sinorhizobium meliloti. Appl. Environ. Microbiol. 71:4910-4913.

Debellé, F., Rosenberg, C., Vasse, J., Maillet, F., Martinez, E., Dénarié, J., and Truchet, G. 1986. Assignment of symbiotic developmental phenotypes to common and specific nodulation (nod) genetic loci of Rhizobium meliloti. J. Bacteriol. 168:1075-1086.

Demont, N., Debellé, F., Aurelle, H., Dénarié, J., and Promé, J. C. 1993. Role of the Rhizobium meliloti nodF and nodE genes in the biosynthesis of lipo-oligosaccharidic nodulation factors. J. Biol. Chem. 268:2013420142.

DeRisi, J. L., Iyer, V. R., and Brown, P. O. 1997. Exploring the metabolic and genetic control of gene expression on a genomic scale. Science 278:680-686.

Dusha, I., and Kondorosi, A. 1993. Genes at different regulatory levels are required for the ammonia control of nodulation in Rhizobium meliloti. Mol. Gen. Genet. 240:435-444.

Finan, T. M., Kunkel, B., De Vos, G. F., and Signer, E. R. 1986. Second symbiotic megaplasmid in Rhizobium meliloti carrying exopolysaccharide and thiamine synthesis genes. J. Bacteriol. 167:66-72.

Fujishige, N. A., Kapadia, N. N., De Hoff, P. L., and Hirsch, A. M. 2006. Investigations of Rhizobium biofilm formation. FEMS (Fed. Eur. Microbiol. Soc.) Microbiol. Ecol. 56:195-206.

Giraud, E., Moulin, L., Vallenet, D., Barbe, V., Cytryn, E., Avarre, J. C., Jaubert, M., Simon, D., Cartieaux, F., Prin, Y., Bena, G., Hannibal, L., Fardoux, J., Kojadinovic, M., Vuillet, L., Lajus, A., Cruveiller, S., Rouy, Z., Mangenot, S., Segurens, B., Dossat, C., Franck, W. L., Chang, W. S., Saunders, E., Bruce, D., Richardson, P., Normand, P., Dreyfus, B., Pignol, D., Stacey, G., Emerich, D., Vermeglio, A., Medigue, C., and 
Sadowsky, M. 2007. Legumes symbioses: Absence of Nod genes in photosynthetic bradyrhizobia. Science 316:1307-1312.

Hassani, R., Prasad, C. K., Vineetha, K. E., Vij, N., Singh, P., Sud, R., Yadav, S., and Randhawa, G. S. 2002. Symbiotic characterization of isoleucine+valine and leucine auxotrophs of Sinorhizobium meliloti. Indian J. Exp. Biol. 40:1110-1120.

Kovach, M. E., Elzer, P. H., Hill, D. S., Robertson, G. T., Farris, M. A., Roop, R. M., 2nd, and Peterson, K. M. 1995. Four new derivatives of the broad-host-range cloning vector pBBR1MCS, carrying different antibiotic-resistance cassettes. Gene 166:175-176.

Krol, E., and Becker, A. 2004. Global transcriptional analysis of the phosphate starvation response in Sinorhizobium meliloti strains 1021 and 2011. Mol. Genet. Genomics 272:1-17.

Kummer, R. M., and Kuykendall, L. D. 1989. Symbiotic properties of amino acid auxotrophs of Bradyrhizobium japonicum. Soil Biol. Biochem. 21:779-782.

Leong, S. A., Williams, P. H., and Ditta, G. S. 1985. Analysis of the 5' regulatory region of the gene for delta-aminolevulinic acid synthetase of Rhizobium meliloti. Nucleic Acids Res. 13:5965-5976.

Lopez, J. C., Grasso, D. H., Frugier, F., Crespi, M. D., and Aguilar, O. M. 2001. Early symbiotic responses induced by Sinorhizobium meliloti iIv $C$ mutants in alfalfa. Mol. Plant-Microbe Interact. 14:55-62.

Maillet, F., Debellé, F., and Dénarié, J. 1990. Role of the nodD and syrM genes in the activation of the regulatory gene nodD3, and of the common and host-specific nod genes of Rhizobium meliloti. Mol. Microbiol. 4:1975-1984.

Meade, H. M., Long, S. R., Ruvkun, G. B., Brown, S. E., and Ausubel, F. M. 1982. Physical and genetic characterization of symbiotic and auxotrophic mutants of Rhizobium meliloti induced by transposon Tn5 mutagenesis. J. Bacteriol. 149:114-122.

Mendel, S., Elkayam, T., Sella, C., Vinogradov, V., Vyazmensky, M., Chipman, D. M., and Barak, Z. 2001. Acetohydroxyacid synthase: A proposed structure for regulatory subunits supported by evidence from mutagenesis. J. Mol. Biol. 307:465-477.

Milcamps, A., Ragatz, D. M., Lim, P., Berger, K. A., and de Bruijn, F. J. 1998. Isolation of carbon- and nitrogen-deprivation-induced loci of Sinorhizobium meliloti 1021 by Tn5-luxAB mutagenesis. Microbiology 144:3205-3218
Miller, J. H. 1972. Pages 352-355 in: Experiments in Molecular Genetics. Cold Spring Harbor Laboratory Press, Cold Spring Harbor, NY, U.S.A.

Mulligan, J. T., and Long, S. R. 1989. A family of activator genes regulates expression of Rhizobium meliloti nodulation genes. Genetics 122:7-18

Oke, V., and Long, S. R. 1999. Bacterial genes induced within the nodule during the Rhizobium-legume symbiosis. Mol. Microbiol. 32:837-849.

Pobigaylo, N., Wetter, D., Szymczak, S., Schiller, U., Kurtz, S., Meyer, F., Nattkemper, T. W., and Becker, A. 2006. Construction of a large signature-tagged mini-Tn5 transposon library and its application to mutagenesis of Sinorhizobium meliloti. Appl. Environ. Microbiol. 72:43294337

Pobigaylo, N., Szymczak, S., Nattkemper, T. W., and Becker, A. 2008. Identification of Genes relevant to symbiosis and competitiveness in Sinorhizobium meliloti using signature-tagged mutants. Mol. PlantMicrobe Interact. 21:219-231.

Randhawa, G. S., and Hassani, R. 2002. Role of rhizobial biosynthetic pathways of amino acids, nucleotide bases and vitamins in symbiosis. Indian J. Exp. Biol. 40:755-764.

Roche, P., Debellé, F., Maillet, F., Lerouge, P., Faucher, C., Truchet, G., Dénarié, J., and Promé, J. C. 1991. Molecular basis of symbiotic host specificity in Rhizobium meliloti: nodH and nodPQ genes encode the sulfation of lipo-oligosaccharide signals. Cell 67:1131-1143.

Sanjuan-Pinilla, J. M., Munoz, S., Nogales, J., Olivares, J., and Sanjuan, J. 2002. Involvement of the Sinorhizobium meliloti leuA gene in activation of nodulation genes by NodD1 and luteolin. Arch. Microbiol. 178:3644.

Terpolilli, J. J., O'Hara, G. W., Tiwari, R. P., Dilworth, M. J., and Howieson, J. G. 2008. The model legume Medicago truncatula A17 is poorly matched for $\mathrm{N}(2)$ fixation with the sequenced microsymbiont Sinorhizobium meliloti 1021. New Phytol. 14:14.

Truchet, G., Michel, M., and Dénarié, J. 1980. Sequential analysis of the organogenesis of lucerne (Medicago sativa) root nodules using symbiotically-defective mutants of Rhizobium meliloti. Differenciation 16:163-172.

Wais, R. J., Wells, D. H., and Long, S. R. 2002. Analysis of differences between Sinorhizobium meliloti 1021 and 2011 strains using the host calcium spiking response. Mol. Plant-Microbe Interact. 15:1245-1252. 